\title{
INTERPRETING POTENTIAL BARIUM SOURCES AT MORMON MESA, NV USING GEOCHEMICAL AND GEOMORPHOLOGICAL DATA
}

INDIA FUTTERMAN, Vassar College

Research Advisor: Kirsten Menking

\section{INTRODUCTION}

Soil profiles, horizons, structures, and geochemistry are direct reflections of environments of formation. Calcic soils are a particularly interesting example which occur in arid to semi-arid environments, and are defined by a subsurface horizon of accumulated secondary calcium carbonate (Machette 1985). With steady climate over time, calcium carbonate accumulates to varying degrees and in varying structures as atmospherically-sourced $\mathrm{Ca}$ (and other) ions are translocated down through the soil profile. Ion translocations reach deeper in wetter climates and shallower in more arid periods, rendering their occurrence at different depths a potential proxy for paleoclimate reconstruction. Steady calcite accumulation over time produces a progressive developmental sequence that can be seen in calcic soils throughout the world, given a tectonically stable soil geomorphic surface. A six-stage model currently describes this developmental sequence, with Stage I horizons as the product of minimal $\mathrm{CaCO} 3$ accumulation and Stage VI as the most highly indurated, physically and chemically complex, and typically oldest horizons that have been broken up and recemented at least once (Machette 1985). This breaking up occurred during wetter climate periods as flash flooding resulted in higher surface physical and chemical erosion rates (Robins et al 2012). The oldest soil profiles contain the most highly-developed petrocalcic horizons which serve as a nearly comprehensive record of climate and geomorphic events, and are thus powerful tools for paleoclimatological reconstruction.

One particularly well-developed, well-preserved petrocalcic soil can be found at Mormon Mesa in the Mojave Desert of southwestern Nevada, USA (Gardner 1972). Developed over the past 4-5 million years in alluvial siliciclastic sediments of the Muddy Creek Formation (Gardner 1972), the Mormon Mesa soil displays the complex morphology of Stage VI petrocalcic horizon development, including brecciation, re-cementation, and vestiges of multiple erosional events. Its complexity has been the subject of many studies (Gardner 1972, Brock-Hon et al., 2012, Robins et al. 2012, and others), investigations which tend to present as many new questions about the development of this ancient soil as they do answers.

Previous work revealed a suite of intriguing minerals present in Mormon Mesa, including authigenic barite (BaSO4) (Brock-Hon et al., 2012). The presence of authigenic barite in this soil is perplexing, as it implies the presence of mobile $\mathrm{Ba}$ ions, which were typically assumed to be insoluble under arid, alkaline conditions (Robins et al., 2012). Pedogenic barite is usually found in low-pH, aquic soils with high base saturation (Stoops and Zavaleta 1978, Sullivan and Koppi 1993), conditions which are not met at Mormon Mesa. However, experimental evidence indicates that $\mathrm{Ba} 2+$ solubility increases in the presence of $\mathrm{Na}+$ and $\mathrm{Mg} 2+$ (Hanor 2000, Blount 1977). Because Ba ions are not readily oxidized nor reduced and do not bind strongly to organic compounds, their transport depends on solubility (Menzie et al. 2008). Considering the net addition of ions over time to Mormon Mesa soil, the influx of ions required to increase Ba solubility for barite authigenesis is plausible.

However, the question remains: what is the source of barium ions in Mormon Mesa soil? Two possibilities 
present themselves: (1) barium could be sourced from Muddy Creek parent material, or (2) Ba ions could be transported to the mesa surface from distal locations.

Barium is not a rare element, most commonly found in the Earth's crust in K-bearing minerals such as alkali feldspars and biotite (Hanor 2000). The underlying Muddy Creek Formation in which the Mormon Mesa soil sequence developed is made up largely of well-sorted, loosely consolidated quartz sand with intercalated beds of claystone and gypsum crusts (Scott 1988). Younger parent materials contributing to the profile consist primarily of siliciclastic alluvium deposited from the Mormon Mountains to the North (Gardner 1972). Soil formation in this region is also heavily influenced by eolian dust inputs (Reynolds et al. 2005), and several studies of dust flux over time in the area point to nearby Owens and Amargosa Valleys as highly probable sources of Ba-rich dust (Reheis et al. 2009; Reheis et al. 2002; Reheis et al 1996). Ba in these dust inputs can be traced back to granitic rocks eroded from the Sierra range (Reheis et al. 2002), and/or from manganese oxides such as hollandite, a constituent of desert varnish and some basaltic lavas that has been found in dusts deposited in southern Nevada (Reheis et al. 1996; Garvie et al. 2008; Fodor et al. 1994; Kabata-Pendias 2011). Additional evidence for eolian or atmospheric ion inputs is the fact that authigenic barite crystals were found primarily in the massive horizon (which caps the sequence), suggesting potential translocation from the surface of the mesa. While the eolian hypothesis is supported by many previous studies, the heterogeneity of the Muddy Creek parent material should be investigated as another potential source of $\mathrm{Ba}$ ions.

The goal of this study is to identify the most likely source of barium ions, which may reveal the nuances of the chemical mobilization pathways that are fundamental to the development of all soils. Additionally, the results of this study may illuminate the processes by which authigenic barium occurs in other calcic soils of the world. It was hypothesized that mapping of elemental concentrations across the mesa surface and across representative soil profiles would show wind-caused variations in geochemistry and reveal potential correlation with geomorphic features. Specifically, a downwind-directional decrease in $\mathrm{Ba}$ concentration would suggest a primarily eolian source for Ba. Conversely, lack of variability of $\mathrm{Ba}$ between horizons or across the mesa surface could support a parent material source.

\section{METHODS}

\section{Map unit description}

A geomorphic map of the mesa surface was created based on remote sensing interpretations, field observations, and using the image classification spatial analyst tool in ArcMap (USDA-FSA-APFO 2017; see Fig. 1). Five geomorphic units were defined: sand dunes, or modern eolian features composed primarily of red quartz sand; gullies, or dendritic, vegetated intermittently wetted subsurface drainage networks; depression pits, or the round, vegetated water collection points for gully drainage; arroyos, or ephemerally wet stream beds actively eroding inwards from the edges of the mesa; and undifferentiated mesa surface, defined as sparsely vegetated eolian sands mantling alluvial fan gravels.

\section{Surface site locations and sampling}

Field work for this study was conducted in June, 2018. 86 samples were collected in total; of these, 36 were analyzed using inductively coupled plasma mass spectrometry (ICP-MS). Two groups of surface samples were collected: geomorphic unit samples collected to ensure adequate representation of the mesa surface in our dataset and to assess the influence of geomorphic processes on soil geochemistry, and surface transects for a systematic study of surface variability, especially as it relates to eolian dust flux. At each sampling site, 200-1000 g of substrate were collected. Two arroyos, three sand dunes, four depression pits, and two drainage gullies were sampled at Mormon Mesa (Fig. 2). Additionally, one sand dune and three depression pits were sampled at adjacent Flat Top Mesa, a separate, isolated remnant of the once more continuous paleo-Mormon Mesa soil geomorphic surface. 20 samples were taken parallel to the northernmost road on Mormon Mesa, at a distance of $0.2 \mathrm{~km}$ north of the road and at intervals of approximately $0.5 \mathrm{~km}$ along the transect (Fig 2). 10 samples were collected along a transect parallel to a shorter, more southern Mormon Mesa road, at 0.2 


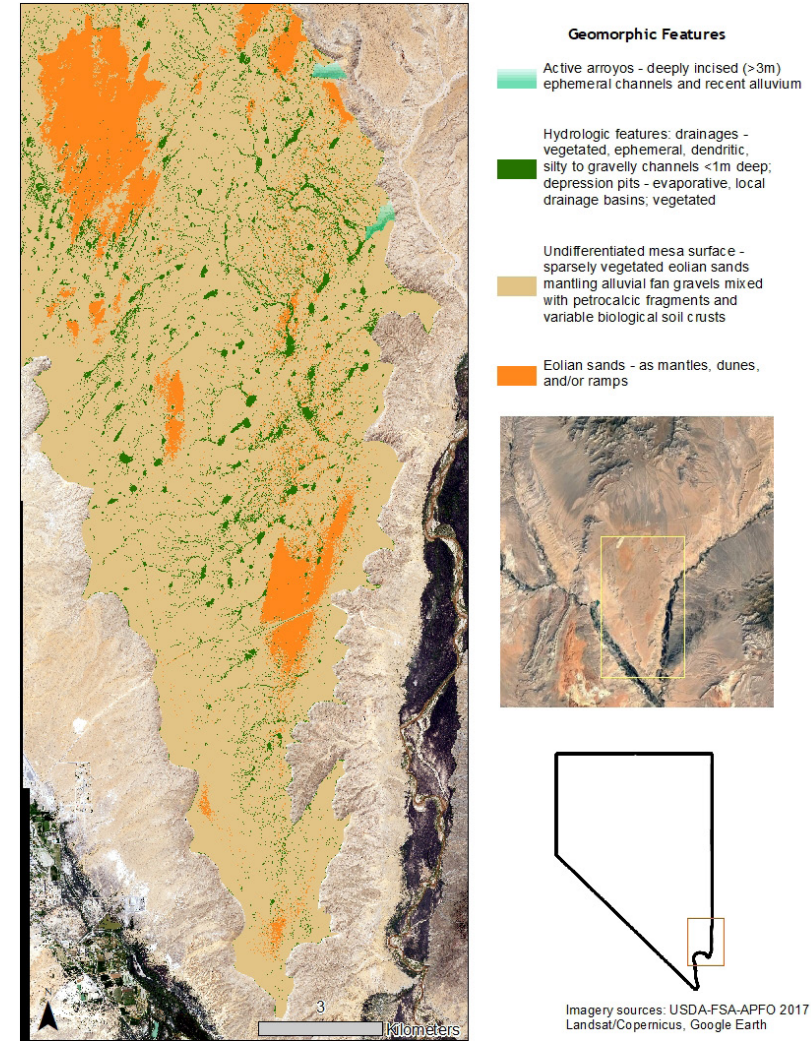

Figure 1: Geomorphic map of mesa surface study area.

$\mathrm{km}$ south of the road and at intervals of approximately $0.4 \mathrm{~km}$ along the transect (Fig. 2). Eight samples were collected along a Flat Top Mesa transect at intervals of approximately $0.25 \mathrm{~km}$.

\section{Profile locations and sampling}

Two complete profiles were sampled at both Mormon Mesa (Riverside and Overton sites) and Flat Top Mesa (Flat Top East and Flat Top West; see Fig. 3). The Riverside and Overton sites are well-studied (Brock-Hon et al. 2012, Robins et al 2012), whereas both Flat Top Mesa profiles had not previously been sampled. 200-1000 g of substrate were collected from each horizon: Muddy Creek (parent material), lower, middle, and upper transitional subhorizons, massive, and brecciated. The highly indurated massive horizon was sampled using a concrete saw.

\section{Laboratory preparation and geochemical analysis}

Unconsolidated samples (e.g., all surface samples) were sieved to separate the fine fraction $(>2 \mathrm{~mm})$ from large organic matter and clasts. The coarse fraction, largely or entirely composed of petrocalcic fragments, was retained. Indurated or partially cemented samples (e.g., all petrocalcic horizon samples) were pulverized in steel rock chippers and disc mills to achieve fine fractionation. $0.5 \mathrm{~g}$ of each sample was digested using EPA Method 3050b, Section 7.5 (for improved solubilities and recoveries of $\mathrm{Ba}$ ). Digests were analyzed for elemental content using the Thermo Scientific iCapRQ ICP-MS run in KED mode at the Chemistry Department of Vassar College.

\section{PRELIMINARY RESULTS}

Elemental concentrations (Table 1) among each of the five depression pit samples tested are fairly consistent. These samples contain notably high concentrations of $\mathrm{Al}, \mathrm{K}$, and Fe. Excluding outliers, depression pit samples also contain comparatively high concentrations of barium and manganese. $\mathrm{Ca}$ concentrations are not notable among these samples. The single playa sample is relatively abundant in $\mathrm{Al}$ and $\mathrm{K} . \mathrm{Ca}$ is very high. Mn concentrations are similar to those in depression pit samples. Fe and $\mathrm{Ba}$ are relatively abundant. $\mathrm{K}, \mathrm{Ca}$, and $\mathrm{Fe}$ concentrations among all undifferentiated surface samples are relatively consistent and tend towards somewhat high concentrations. $\mathrm{Al}, \mathrm{Mn}$, and $\mathrm{Ba}$ concentrations vary among these samples. Al ranges from moderate to high abundance; $\mathrm{Mn}$ ranges from low to moderate abundance, and $\mathrm{Ba}$ ranges from low to moderate concentration. Concentrations of all elements, besides $\mathrm{Fe}$, were relatively low among sand dune samples. $\mathrm{Ba}$ concentrations are lowest among these samples. $\mathrm{Ca}$ concentrations range from low to moderate among samples. Concentrations of other elements remain consistently low among samples. Elemental concentrations between the two drainage samples tested are quite consistent. $\mathrm{Al}, \mathrm{K}, \mathrm{Ca}$, and $\mathrm{Mn}$ are present at moderate concentrations. Fe and $\mathrm{Ba}$ are present at moderate to high concentrations. Some elemental concentrations between both arroyo samples are inconsistent. $\mathrm{Al}$ ranges from low to moderate, and $\mathrm{Mn}$ ranges from low to very high. $\mathrm{Ca}, \mathrm{Fe}$, and $\mathrm{Ba}$ are consistently relatively moderate.

Elemental concentrations vary among the horizon samples tested (Fig. 3 and Table 1). Among these samples, $\mathrm{Al}, \mathrm{K}$, and $\mathrm{Fe}$ concentrations are highest in the rubble horizon. $\mathrm{Ca}$ cconcentrations are highest in 
the massive and transitional horizons. Mn is notably high in the transitional horizon, and Fe is particularly high in the rubble layer. The massive horizon contains by far the highest Ba concentration, with half as much in the transitional layer, and comparatively very little in the rubble layer. Between the two horizons, there is a general decreasing trend in $\mathrm{Ba}$ concentration with depth.

\section{DISCUSSION}

Preliminary ICP-MS results of Ba and other elemental concentrations present a puzzle. Because this study is primarily concerned with barium sources, interpretation will focus of Ba concentrations among samples and any apparent relationship between $\mathrm{Ba}$ and the presence of other ions. The high Ba concentrations (as much as $428.4 \mathrm{ppb}$ ) detected in the massive and transitional horizons are consistent with previously published observations of barite crystals in these

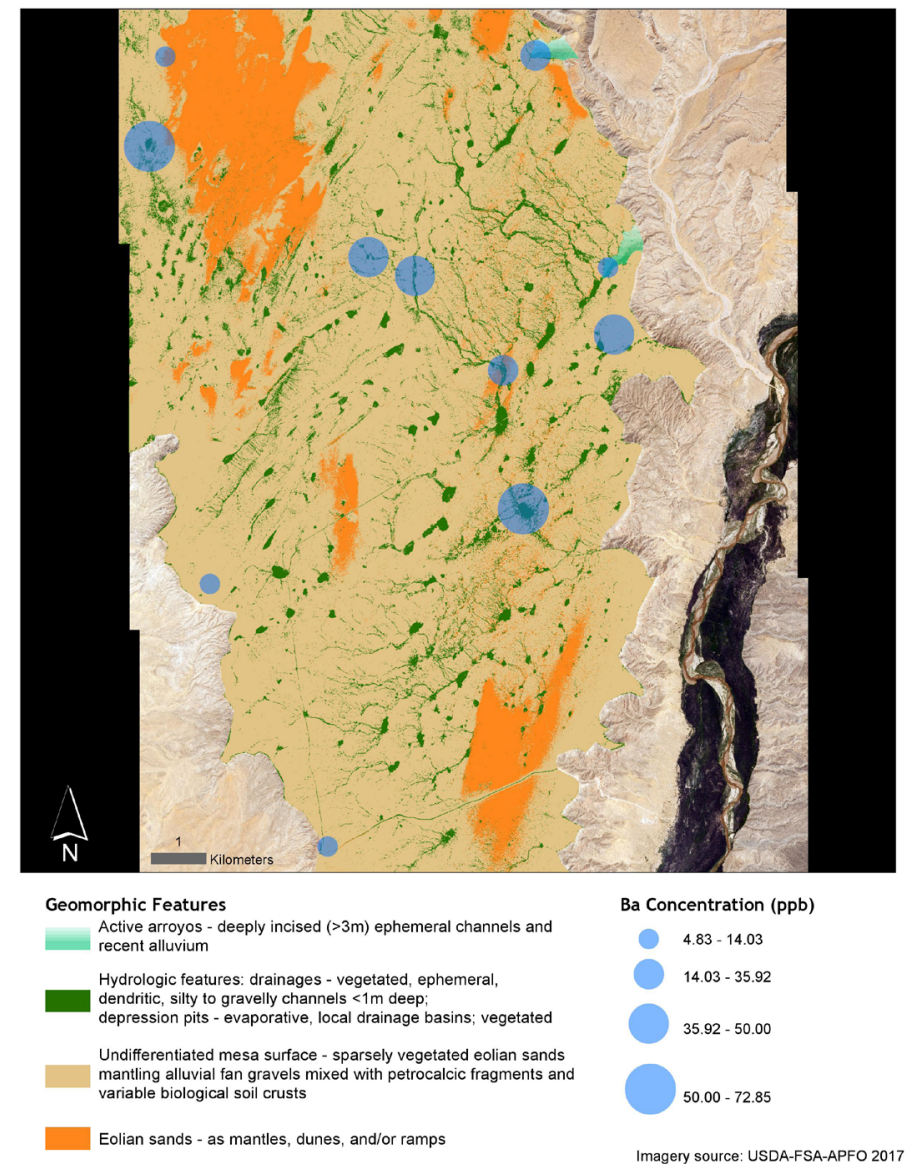

Figure 2: Selected elemental concentrations (ppb) from surface transect and geomorphic feature samples, Mormon Mesa.
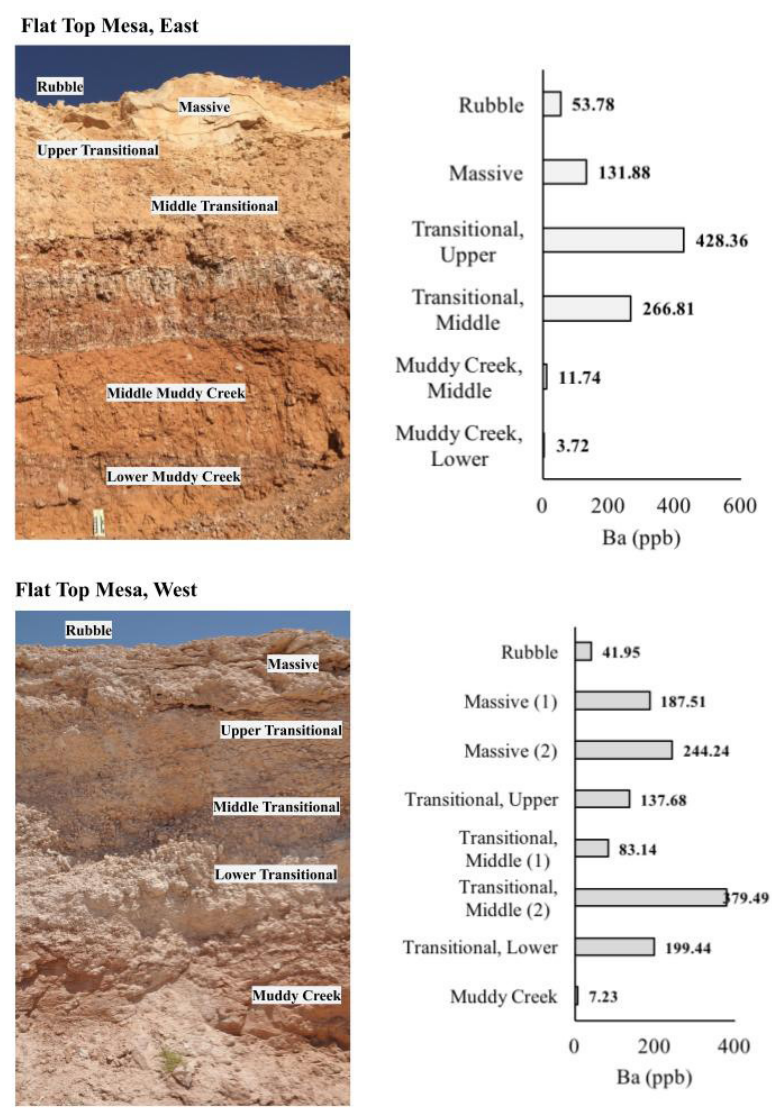

Figure 3: Ba concentrations within soil horizons: Flat Top Mesa East and West.

horizons from SEM imagery (Brock-Hon et al., 2012). These high Ba concentrations are likely the result of continuous accumulation of atmospherically-sourced ions in geomorphologically stable, relatively shallow horizons over an extended period of time. As an actively eroding surface, the uppermost rubble layer of the Mormon Mesa soil sequence would not be able to accumulate much atmospherically-sourced $\mathrm{Ba}$. Additionally, according to the eolian/atmosphericallysourced Ba hypothesis, with increasing profile depth one would expect to see decreasing Ba concentrations as the translocated ions are sequestered in the shallower horizons.

\section{Relatively high concentrations of Ba among} depression pit samples perhaps point to the significance of hydrology in modern Ba solubility trends. As fluid collection points within an apparent hydrological network of drainage gullies on the mesa surface, they are likely to have more concentrated 


\begin{tabular}{lcccccc} 
& $\mathbf{A l}$ & $\mathbf{K}$ & $\mathbf{C a}$ & $\mathbf{M n}$ & $\mathbf{F e}$ & $\mathbf{B a}$ \\
Depression pit & 3693.18 & 863.83 & 4276.66 & 114.80 & 4268.03 & 72.85 \\
Depression pit & 3291.90 & 653.08 & 7057.28 & 108.50 & 3756.95 & 65.38 \\
Depression pit & 2738.23 & 558.79 & 3908.38 & 95.77 & 3528.28 & 50.00 \\
Depression pit & 3808.70 & 912.06 & 5758.02 & 119.83 & 4289.36 & 69.70 \\
Depression pit & 2080.57 & 372.17 & 8789.04 & 75.58 & 2946.28 & 42.44 \\
Playa & 2937.69 & 631.44 & 26698.07 & 101.44 & 3580.14 & 50.48 \\
Undifferentiated surface & 1958.53 & 353.90 & 7281.74 & 71.31 & 3021.84 & 38.76 \\
Undiff. surface & 2095.99 & 326.75 & 9497.81 & 70.49 & 3046.29 & 48.21 \\
Undiff. surface & 919.56 & 114.95 & 2072.41 & 32.67 & 2071.36 & 14.03 \\
Undiff. surface & 1641.92 & 288.32 & 6617.07 & 107.62 & 2656.71 & 29.13 \\
Sand dune & 620.35 & 62.34 & 803.15 & 31.77 & 2917.76 & 8.52 \\
\hline Sand dune & 282.58 & 16.87 & 1936.69 & 16.32 & 1139.15 & 4.83 \\
\hline Sand dune & 559.90 & 87.13 & 339.20 & 18.59 & 1475.05 & 6.75 \\
\hline Sand dune & 345.43 & 14.68 & 1504.20 & 12.59 & 844.36 & 4.69 \\
\hline Transitional horizon & 937.62 & 63.99 & 65070.56 & 255.35 & 667.86 & 266.81 \\
Massive horizon & 892.23 & 34.36 & 54813.03 & 6.45 & 564.42 & 428.36 \\
Rubble horizon & 1813.87 & 283.04 & 13032.41 & 50.78 & 2706.00 & 53.78 \\
Drainage gully & 2610.98 & 557.65 & 5137.50 & 98.78 & 3501.64 & 48.39 \\
Drainage gully & 1894.83 & 394.62 & 3409.72 & 78.03 & 2855.12 & 35.92 \\
Arroyo & 1483.18 & 210.90 & 9020.06 & 36.88 & 2056.70 & 30.16 \\
Arroyo & 571.27 & 142.75 & 16597.30 & 753.81 & 1193.06 & 12.80 \\
& & & & & & \\
\hline
\end{tabular}

Table 1: ICP-MS results for selected elemental concentrations (ppb) of selected samples.

dissolved ions. These may prove to be ideal circumstances for increasing the solubility of barium, explaining why the data show somewhat elevated Ba concentrations among these samples, and also accounting for the somewhat lower Ba concentrations in drainage gully samples. If $\mathrm{Ba}$ were primarily sourced from the Muddy Creek Formation, these concentrations would be low relative to those parent materials. Future studies should also investigate the influence of biologically-aided mineral precipitation on elemental concentrations in these sporadically moistened locations.

The relatively high $\mathrm{Ba}$ concentration in the playa sample may support the eolian hypothesis as well, as the fine evaporitic sediments in playas to the west of the mesa may be blown onto the mesa surface. Future studies should sample additional adjacent playas for more comprehensive geochemical data. Further support for the eolian hypothesis stems from the presence of barium in "undifferentiated surface" samples. Complete transects are being analyzed to assess a downwind trend in decreasing $\mathrm{Ba}$ concentration, which would also lend credence to the eolian hypothesis.

The apparently very low elemental concentrations among sand dune samples may be attributed to the fact that substrate samples, composed mainly of silicate minerals, were not digested in hydrofluoric acid. Complete digestions of all samples would yield more accurate data, and should be pursued in subsequent studies.

The lack of consistency in the geochemical makeup of both arroyo samples may be due to the active erosion occurring at these sites only. Active erosion would likely result in a chaotic mixing of lithic fragments, soil horizons material, and transported grains, producing somewhat outlier results.

\section{CONCLUSIONS}

This study incorporated data from ancient soil horizons as well as geomorphically active surface sediments to investigate the potential sources of $\mathrm{Ba}$ for authigenic barite in the massive horizon of this soil (Brock-Hon et al. 2012). By mapping the spatial variations in the concentration of barium and other associated elements in surface and profile samples, potential relationships between geomorphic features and chemical composition could be illuminated. ICPMS data suggest that $\mathrm{Ba}$ ions are more concentrated towards the surface of the mesa, in the transitional, massive, and rubble horizons, as well as in the depression pits that dot the mesa surface. Somewhat elevated $\mathrm{Ba}$ concentrations in depression pit samples may also suggest a hydrological component to barite neoformation in Mormon Mesa soils. As more samples are analyzed and results are mapped, more definitive conclusions may be drawn. Identifying the mechanisms that drive barite authigenesis can deepen our understanding of soil formation and ion mobilization, as well as allow us to anticipate the geochemical impacts of climate change on our soils. 


\section{ACKNOWLEDGEMENTS}

This material is based upon work supported by the Keck Geology Consortium and the National Science Foundation under Grant No. 1659322. Special thanks to Colin R. Robins, Penelope Vorster, Ethan Conley, and Kurt Crandall for their support in the field and laboratory. Major support from the Keck Geology Consortium was provided by Cam Davidson, Karl Wirth, Marga Miller, and Jonathan Harris. This project would not have been possible without the advising of Kirsten Menking in the Vassar College Earth Science Department. Other Vassar staff involved in this project include Rick Jones, Jeff Walker, and Joseph Tanski. Neil Curri provided invaluable assistance with GIS operations. Special thanks to Dr. Karen Wovkulich for her patient help with ICP and XRF analyses. Thanks also to Amy Brock-Hon for her foundational research on barite in Mormon Mesa soils. Matthew Rahn Manon and the Union College Department of Geology provided access to laboratory space and use of their handheld XRF. Permission to sample was provided by the Clark County Bureau of Land Management through a letter of understanding (680 NVS0100).

\section{REFERENCES}

Beattie, J., \& Haldane, A. (1958). The occurrence of palygorskite and barytes in certain parna soils of the Murrumbidgee region, new South Wales". The Australian Journal of Science, 20, 274-275.

Blount, C. (1977). Barite solubilities and thermodynamic quantities up to $300 \mathrm{C}$ and 1400 bars. American Mineralogist, 62, 942-947.

Brock-Hon, A., Robins, C.R., \& Buck, B.J. (2012). Micromorphological investigation of pedogenic barite in Mormon Mesa petrocalcic horizons, Nevada USA: Implication for genesis. Geoderma, 179-180, 1-8.

Buck, B., Lawton, T., \& Brock, A. (2010). Evaporitic paleosols in continental strata of the Carroza Formation, La Popa Basin, Mexico: Record of Paleogene climate and salt tectonics. GSA Bulletin, 122(7/8), 1011-1026.

Fodor, R., Jacobs, R., \& Bauer, G. (1994). Hollandite in Hawaiian basalt: a relocation site for weathering-mobilized elements. Mineralogical Magazine, 58, 589-596.

Gardner, L. (1972). Origin of the Mormon Mesa Caliche, Clark County, Nevada. Geological Society of America Bulletin, 83, 143-156.

Garvie, L., Burt, D., \& Buseck, P. (2008). Nanometerscale complexity, growth, and diagenesis in desert varnish. Geology, 36(3), 215-218.

Jones, R. (1986). Barium in Illinois Surface Soils. Soil Science Society of America Journal, 50, 10851087.

Kabata-Pendias, A. (2011). Trace Elements in Soils and Plants. (4, Ed.) Boca Raton, FL: CRC Press.

Machette, M. (1985). Calcic soils of the southwestern United States. Geological Society of America Special Paper, 203, 1-21.

Menzie, C., Southworth, B., Stephenson, G., \& Feisthauer, N. (2008). The Importance of Understanding the Chemical Form of a Metal in the Environment: The Case of Barium Sulfate (Barite). Human and Ecological Risk Assessment, 14, 974-991.

Reheis, M., Budahn, J., \& Lamothe, P. (2002). Geochemical evidence for diversity of dust sources in the southwestern United States. Geochimica et Cosmochimica Acta, 66(9), 15691587.

Reheis, M., Budahn, J., Lamothe, P., \& Reynolds, R. (2009). Compositions of modern dust and surface sediments in the Desert Southwest, United States. Journal of Geophysical Research, 114, 1-20.

Reheis, M., Goodmacher, J., Harden, J., McFadden, L., Rockwell, T., Shroba, R., . . . Taylor, E. (1995). Quaternary soils and dust deposition in southern Nevada and California. GSA Bulletin, 107(9), 1003-1022.

Reynolds, R., Reheis, M., Yount, J., \& Lamothe, P. (2006). Composition of aeolian dust in natural traps on isolated surfaces of the central Mojave 
Desert - sights to mixing, sources, and nutrient inputs. Journal of Arid Environments, 66, 42-61.

Robins, C., Brock-Hon, A., \& Buck, B. (2012).

Conceptual Mineral Genesis Models for Calcic Pendants and Petrocalcic Horizons, Nevada. Soil Science Society of America Journal, 1-17.

Stoops, G., \& Zavaleta, A. (1978).

Micromorphological evidence of barite neoformation in soils. Geoderma, 20, 63-70.

Sullivan, L., \& Koppi, A. (1995). Micromorphology of authigenic celestobarite in a duripan from central Australia. Geoderma, 64, 357-361. 